\title{
Effect of chloroquine on insulin and glucose homoeostasis in normal subjects and patients with non-insulin-dependent diabetes mellitus
}

\author{
G D SMITH, T A S AMOS, R MAHLER, T J PETERS
}

\begin{abstract}
Plasma glucose, insulin, and $\mathbf{C}$ peptide concentrations were determined after an oral glucose load in normal subjects and in a group of patients with non-insulin-dependent diabetes mellitus before and during a short course of treatment with chloroquine. In the control group there was a small but significant reduction in fasting blood glucose concentration but overall glucose tolerance and hormone concentrations were unaffected. In contrast, the patients with non-insulin-dependent diabetes mellitus showed a significant improvement in their glucose tolerance, which paralleled the severity of their diabetes.

This response seems to reflect decreased degradation of insulin rather than increased pancreatic output. These observations suggest that treatment with chloroquine or suitable analogues may be a new approach to the management of diabetes.
\end{abstract}

\section{Introduction}

The liver is a major target organ for insulin, removing up to half of available circulating insulin. ${ }^{1}$ This hepatic uptake is mediated by receptors, and once the insulin-receptor complex has been internalised the hormone undergoes rapid degradation and clearance from the liver. ${ }^{2}$ In the rat chloroquine causes hepatic retention of insulin, ${ }^{3}$ an effect which has been ascribed to the lysosomatotropic action of chloroquine. ${ }^{4} \mathrm{We}$ have recently shown, however, that chloroquine directly affects an insulin degrading activity $^{5}$ associated with a class of endocytic vesicle known as the ligandosome,${ }^{6}$ into which insulin is rapidly internalised.

Because of the striking inhibitory effect of chloroquine on the hepatic degradation of insulin we investigated the effect of short term treatment with chloroquine on glucose homoeostasis in normal controls and patients with type II diabetes mellitus.

\section{Patients and methods}

Six patients with mild, non-insulin-dependent diabetes mellitus were selected for the study. The table shows the clinical data at referral. None of the patients was receiving any drugs, diabetic control being achieved by diet alone. Data for these patients were compared with those for six healthy members of the laboratory staff, who had a median age of 34 (range 27-55) and were not taking any drugs. The study was approved by the Harrow Health Authority ethical committee, and all subjects gave informed consent to the study.

Clinical details of patients

\begin{tabular}{cccccc}
\hline $\begin{array}{c}\text { Case } \\
\text { No }\end{array}$ & Sex & $\begin{array}{c}\text { Age } \\
\text { (years) }\end{array}$ & $\begin{array}{c}\text { Year of } \\
\text { presentation }\end{array}$ & $\begin{array}{c}\text { Quetelet's } \\
\text { index } \\
\left(\mathbf{k g} / \mathbf{m}^{2}\right)\end{array}$ & $\begin{array}{c}\text { Glycosylated } \\
\text { haemoglobin } \\
(\%)\end{array}$ \\
\hline 1 & $M$ & 61 & 1976 & $27 \cdot 2$ & $10 \cdot 1$ \\
2 & $M$ & 65 & 1981 & $24 \cdot 2$ & $11 \cdot 5$ \\
3 & F & 49 & 1982 & $32 \cdot 9$ & $11 \cdot 2$ \\
4 & $M$ & 62 & 1984 & $31 \cdot 2$ & $15 \cdot 4$ \\
5 & $M$ & 46 & 1983 & $28 \cdot 1$ & $7 \cdot 9$ \\
6 & $M$ & 57 & 1982 & $28 \cdot 4$ & $10 \cdot 4$ \\
\hline
\end{tabular}

^Normal values: Quetelet's index 20-25, glycosylated haemoglobin 5·5-8.5\%.

After an overnight fast each subject drank $200 \mathrm{ml}$ of water containing $75 \mathrm{~g}$ glucose. Six blood samples were obtained between 0 and 180 minutes. Chloroquine phosphate ( $150 \mathrm{mg}$ chloroquine base) was then taken orally four times a day for two and a half days $(1.5 \mathrm{~g}$ chloroquine in total). The glucose tolerance test was then repeated on the day when the last dose of chloroquine was given. The blood samples were assayed for glucose by the routine hexokinase method (coefficient of variation $=2 \cdot 5 \%$ ). Plasma samples prepared at the same time were assayed for insulin 
(Amersham International, Amersham, UK, coefficient of variation $=6.5 \%$ ) and $C$ peptide (Guildhay Anti-Sera, Guildford, UK, coefficient of variation $=9 \cdot 0 \%)$.

\section{Results}

Figure 1 shows the mean glucose, insulin, and $\mathrm{C}$ peptide concentrations before and after treatment with chloroquine in the controls during the test. There was little difference in the measurements before and after treatment with chloroquine, although the fasting concentrations of glucose were significantly different at the $1 \%$ limit. There was no significant difference at the other times.
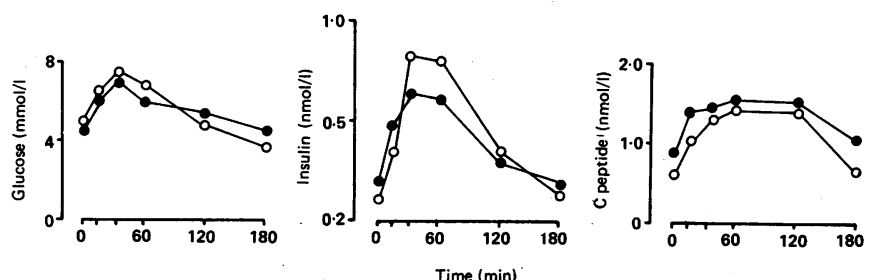

FIG 1-Blood glucose, insulin, and C peptide concentrations in controls after glucose challenge. Mean values $(n=6)$ are shown for each time point of ora glucose tolerance test before (-O-O- $)$ and during (-Otreatment. For fasting glucose values $\mathrm{p}=0.006$ (paired $t$ test).

Figure 2 shows the glucose tolerance curves for the six non-insulindependent patients with diabetes mellitus before and during treatment with chloroquine. In all except the patient in case 6 treatment with chloroquine resulted in a pronounced improvement in the glucose tolerance, as indicated by the shaded areas in figure 2 . The calculated difference in the area under the glucose tolerance curve before and after treatment with chloroquine represents each subject's response to the drug (fig 3). A negative value indicates improved glucose tolerance. Control values were grouped around zero, but all values for the patients with non-insulin-dependent diabetes mellitus were negative. The difference between the two groups was highly significant $(\mathrm{p}=0.0036)$.

Figure 4 compares the plasma insulin and $C$ peptide concentrations
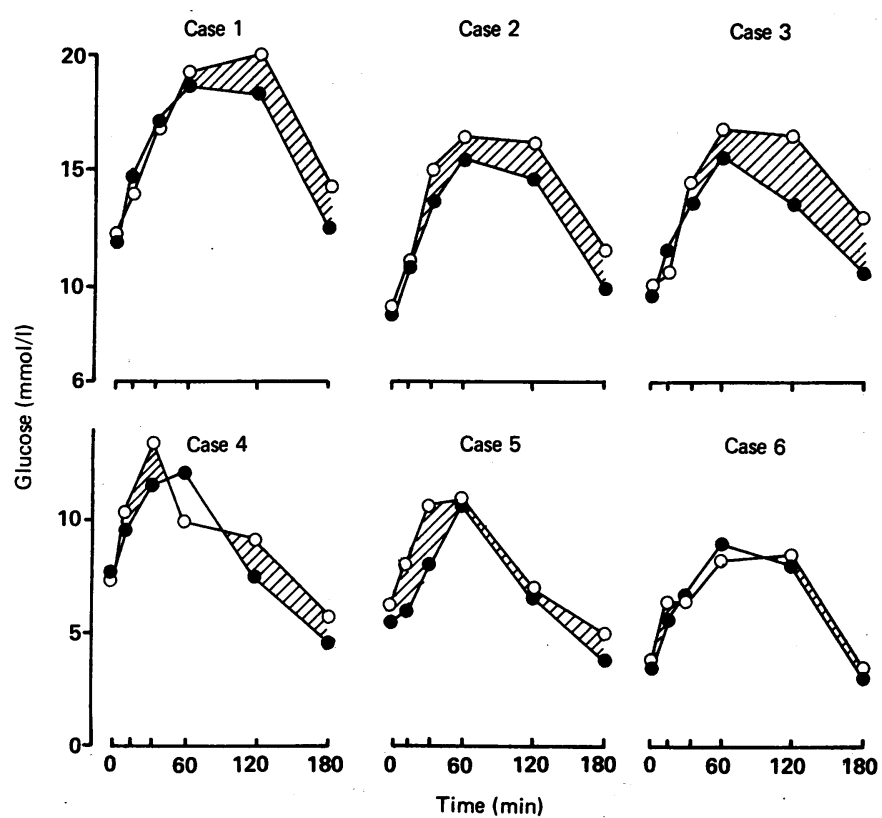

FIG 2-Blood glucose concentrations for patients with non-insulin-dependent diabetes mellitus during oral glucose tolerance test. Values are shown for each time point of test after glucose challenge in patients with non-insulin-dependent diabetes mellitus before ( $\left(-\mathrm{O}_{-}-\right.$) and during ( $-\mathrm{O}-$ ) chloroquine treatment. Shaded area indicates an improvement in glucose tolerance. during the test before and after treatment. The results are again expressed as the difference in the total area under the curves. Compared with the controls, the patients showed a significant increase in total plasma insulin $\varrho$ concentration $(p=0.031)$. There was no significant difference, however, in $c$ the concentrations of plasma $C$ peptide between the two groups $(p=0 \cdot 14)$.

\section{Discussion}

Resistance to insulin is one of the main distinguishing features of non-insulin-dependent diabetes mellitus. ${ }^{7}$ Only in rare cases has $\stackrel{\oplus}{\rightarrow}$

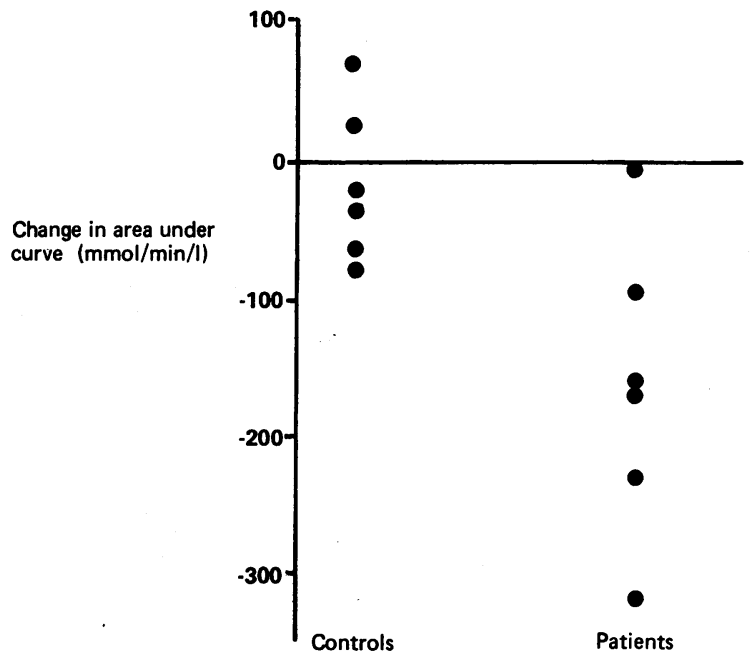

FIG 3-Comparison of glucose tolerance in patients with non-insulin-dependent diabetes mellitus and controls. The graph shows the difference in the total area under glucose tolerance curve during chloroquine treatment for the two groups $(p=0.0036$, Wilcoxon's rank sum test).
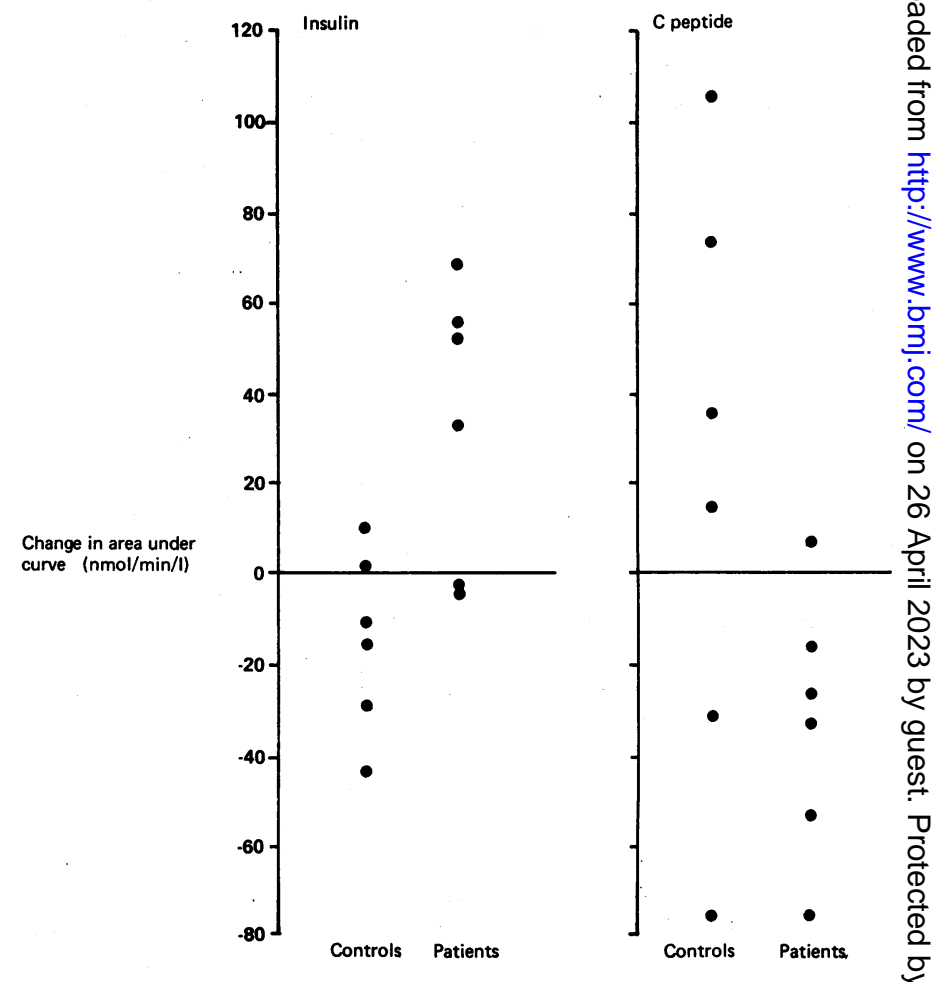

FIG 4 - Comparison of insulin and $C$ peptide concentrations in patients with non-insulin-dependent diabetes mellitus and controls. The graph shows the difference during chloroquine treatment in the total area under the curve obtained by plotting plasma insulin concentrations $(p=0.031$, Wilcoxon's rank sum test) and $C$ peptide concentrations ( $p=0 \cdot 14$, Wilcoxon's rank sum test) against time after oral glucose tolerance test was started. 
insulin resistance in patients with non-insulin-dependent diabetes mellitus been ascribed to abnormal islet cell products or circulating insulin antagonists. In most cases it is thought to be caused by a combination of a decreased number of receptors and a postreceptor defect. The rationale for the present study was that, although the sequence of postreceptor events is not clear, a drug able to inhibit postreceptor degradation might promote the metabolic effects of insulin and overcome, at least in part, the insulin resistance. There is some precedence for this approach, as Blazar et al showed a dramatic decrease in the insulin resistance of a patient with insulin dependent diabetes mellitus after treatment with chloroquine. ${ }^{8}$

In the control group administration of chloroquine had negligible effects on glucose homoeostasis and plasma insulin and $\mathrm{C}$ peptide concentrations. This supports the findings of Philips $e t$ al, who showed that, unlike quinine, which can produce severe hypoglycaemia, infusion of chloroquine and other synthetic antimalarial drugs has no appreciable effect on plasma glucose and insulin concentrations. ${ }^{9}$ The diabetic patients in this study experienced significant changes in glucose tolerance after treatment with chloroquine, the largest changes occurring in those who showed the greatest glucose intolerance before treatment. These changes represent a median decrease of $8.9 \%$ (range $0.4 \%$ to $12 \cdot 1 \%$ ) in the glucose intolerance of this group of patients.

The improvement in glucose tolerance in the patients with noninsulin-dependent diabetes mellitus was reflected by a significant increase in plasma insulin concentration during the glucose tolerance test. The fact that the $\mathrm{C}$ peptide concentrations did not show a similar increase argues against increased output of insulin as a mode of action of the chloroquine. The insulin assay used in this study also detects proinsulin, and the raised values may therefore reflect increased circulatory proinsulin. This would imply that chloroquine had interfered with the proteolytic conversion of proinsulin to insulin in the Golgi apparatus of the islet cells and would be expected to have a deleterious effect on glucose homoeostasis rather than the beneficial effect shown here.

Although the glucose tolerance improved significantly on glucose challenge, there was no apparent change in the basal fasting glucose concentration. This may be connected with the short duration of the treatment with chloroquine and is now being investigated. Whether or not the effect of chloroquine is hepatic or peripheral cannot be determined from this study; inhibition of intraligandosomal breakdown is certainly a possible mechanism.

Interestingly, in the controls and the one diabetic patient with near normal glucose tolerance chloroquine had negligible effects on glucose tolerance. This suggests that in non-diabetic subjects the normal homoeostatic mechanisms responsible for insulin-glucose regulation may compensate for perturbations in the insulin concentrations that may be caused by chloroquine and thus prevent the onset of hypoglycaemia.

The results of this study suggest that treatment of non-insulindependent diabetes mellitus with chloroquine or suitable analogues may provide a means of diabetic control that does not entail stimulation of pancreatic insulin production. In particular, our results suggest that chloroquine may be useful in diminishing postprandial hyperglycaemia in obese patients with non-insulindependent diabetes mellitus.

\section{References}

1 Field JB. Extraction of insulin by liver. Annu Rev Med 1973;24:309-14.

2 Caro JF, Muller G, Glennon JA. Insulin processing by the liver. $\mathcal{F}$ Biol Chem 1982;257:8459-66

3 Terris S, Hoffman C, Steiner DF. Mode of uptake and degradation of ${ }^{125} \mathrm{I}$-labelled insulin by isolated hepatocytes and $\mathrm{H} 4$ hepatoma cells. Can F Biochem 1979;57:459-68.

4 Dennis PA, Aronson NN. The effects of low temperature and chloroquine on ${ }^{125} \mathrm{I}$-insulin degradation by the perfused rat liver. Arch Biochem Biophys 1981;212:170-6.

5 Pease RJ, Smith GD, Peters TJ. Degradation of endocytosed insulin in rat liver is mediated by low density vesicles. Biochem $\mathcal{f}$ 1985;228:137-46.

6 Smith GD, Peters TJ. The localization in rat liver of alkaline phosphodiesterase to a discrete organelle implicated in ligand internalization. Biochim Biophys Acta 1982;716:24-30.

7 Kahn OR. Insulin resistance: a common feature of diabetes mellitus. $N$ Engl f Med 1986;315: 252-3.

8 Blazar BR, Whitley CB, Kitabchi AE, et al. In vivo chloroquine induced inhibition of insulin degradation in a diabetic patient with severe insulin resistance. Diabetes 1984;33:1133-7.

9 Philips RE, Looareesuwan S, White NJ, et al. Hypoglycaemia and antimalarial drugs: quinidine and release of insulin. BrMed $\mathcal{F}$ 1986;292:1319-21.

\title{
Effect of single high dose infusions of aminohydroxypropylidene diphosphonate on hypercalcaemia caused by cancer
}

\author{
BRIAN M J CANTWELL, ADRIAN L HARRIS
}

\begin{abstract}
Single intravenous infusions of $\mathbf{3 0} \mathbf{~ m g}$ aminohydroxypropylidene diphosphonate were given to 16 patients who had malignant hypercalcaemia to assess host tolerance and the effect on serum calcium concentration. Ten of these patients also received intravenous rehydration or corticosteroids, or both. The serum calcium concentrations decreased significantly after treatment with aminohydroxypropylidene diphosphonate. Ten patients became normocalcaemic (normal range, adjusted for serum
\end{abstract}

University Department of Clinical Oncology, Newcastle General Hospital, Newcastle upon Tyne NE4 6BE

BRIAN M J CANTWELL, MD, MRCP, lecturer in clinical oncology

ADRIAN L HARRIS, DPHIL, FRCP, professor of clinical oncology

Correspondence to: Dr Cantwell. albumin, $2 \cdot 25-2 \cdot 75 \mathrm{mmol} / \mathrm{l})$, two became hypocalcaemic, three showed decreases in serum calcium concentrations of more than $0.75 \mathrm{mmol} / \mathrm{l}$, and one showed a decrease of more than 0.55 $\mathrm{mmol} / \mathrm{l}$. Only one patient had a minimum concentration greater than $2.77 \mathrm{mmol} / \mathrm{l}$. Aminohydroxypropylidene diphosphonate was effective in metastatic and non-metastatic hypercalcaemia, and its hypocalcaemic effect was prolonged in some cases. There were no appreciable side effects.

Single high dose infusions of aminohydroxypropylidene diphosphonate could replace conventional daily lower dose infusions, but the optimum frequency of high dose infusions remains to be determined.

\section{Introduction}

Hypercalcaemia associated with malignancy was the most common type of hypercalcaemia identified in a large hospital survey. ${ }^{1}$ The treatment of hypercalcaemia associated with malignancy may be 